\title{
Pemerolehan Kosa Kata Anak Autism Spectrum Disorder (ASD)
}

\author{
Heny Sulistyowati ${ }^{1}$, Diana Mayasari ${ }^{1}$, Susi Dari Hastining ${ }^{1}$ \\ Pendidikan Bahasa Indonesia, Sekolah Tinggi Keguruan dan Ilmu Pendidikan PGRI \\ Jombang, Indonesia(1) \\ DOI: $10.31004 /$ obsesi.v6i4.2374
}

\begin{abstract}
Abstrak
Perkembangan bahasa pada anak mulai kelihatan pada usia sekitar satu tahun ketika mereka mulai mampu berjalan dan pada waktu anak mampu mengeluarkan kata-kata pertama. Autis ringan memiliki gangguan dalam berbahasa sehingga penyerapan bahasa anak autis berbeda dengan anak normal. Menggunakan pendekatan studi kasus, penelitian ini bertujuan untuk memberikan gambaran pemerolehan kosakata anak autis kategori ringan. Pengambilan data dilakukan dengan teknik wawancara dan observasi. Menggunakan lembar pengamatan yang biasa digunakan oleh sekolah, subyek diberikan media berupa gambar benda (buah, hewan, kendaraan, dan benda lain yang sering dijumpai anak). Selain itu, juga ditunjukkan gambar aktivitas sehari-hari. Hasil penelitian menunjukkan bahwa kosakata kerja dan benda yang ditunjukkan anak autis mengalami perubahan yakni ada huruf yang hilang dan kata yang berubah hurufnya. Implikasi studi ini dapat digunakan oleh pendidik dan orangtua untuk memahami kondisi perkembangan bahasa anak autis serta dapat memberikan langkah stimulasi yang tepat.
\end{abstract}

Kata Kunci: autis ringan; pemerolehan kosakata; perkembangan bahasa

\begin{abstract}
Language development in children can be seen for one years old when they can walk and produce the first words. A mild autism child has language disorder so the language absorption is different from the other. Used the case study, this research aimed to give the description about the vocabulary acquisition in a mild autism child. Data were taken by interview and observation. Using observation sheet used to by the school, subject was given object picture as the media (fruits, animals, and etc). Moreover, also showed some of daily activities pictures. Result show that verb and noun change in the pronunciation by the mild autism children. There are letters missing and words that change letters. The implication of this study can be used by the teacher and parent to understand the language development of autism children and can give the appropriate stimulation.
\end{abstract}

Keywords: mild autism; vocabulary acquisition; language development

Copyright (c) 2022 Heny Sulistyowati, et al.

$\triangle$ Corresponding author:

Email Address : heny.sulistyowati@gmail.com (Jombang, Indonesia)

Received 4 November 2021, Accepted 12 February 2022, Published 14 February 2022 


\section{PENDAHULUAN}

Pemerolehan bahasa atau akuisisi berlangsung di dalam otak seseorang ketika memperoleh bahasa pertamanya atau bahasa ibu (Hikmawati, 2014). Seseorang mendengar sebuah kosakata, kemudian ia merekam lalu menggunakannya di saat yang tepat sesuai dengan kondisi percakapan yang sedang berlangsung. Hal inilah yang nantinya menjadi modal awal untuk untuk berbahasa. Pada anak-anak, pemerolehan bahasa memungkinkan terjadinya proses untuk mengembangkan keterampilan bahasa (Mar'at, 2005). Kemampuan perolehan kosakata hanya dapat dilakukan secara tidak langsung melalui observasi kata yang diujarkan. Kita dapat mengetahui perbendaharaan kata apa saja yang dikuasai oleh seorang anak melalui ujaran tersebut. Oleh karena itu, proses pemerolehan bahasa dipengaruhi oleh kesiapan seorang anak di dalam dirinya sendiri Rahmania (Liza et al., 2020).

Perkembangan setiap anak dalam memperoleh bahasa menggunakan pola yang berbeda antara anak satu dengan anak yang lain (Callen \& Miller, 2021). Kesulitan atau kemudahan selalu menyertai perkembangan anak dalam memperoleh pembelajaran bahasa. Perkembangan bahasa pada anak mulai kelihatan pada usia sekitar satu tahun ketika anak mulai mampu berjalan dan pada waktu anak mampu mengeluarkan kata-kata pertama. Kondisi ini tentu akan berbeda pada anak-anak yang mengalami gangguan berbahasa sejak lahir seperti anak-anak berkebutuhan khusus (ABK). Pada kasus anak Autis ringan memiliki gangguan dalam berbahasa sehingga penyerapan bahasa anak autis berbeda dengan anak normal. Anak Autis ringan masih bisa menunjukkan sedikit respon kepada orang yang mengajak berbicara walaupun hanya terjadi sesekali. Lebih lanjut, sebuah studi melaporkan bahwa anak autis mengalami keterbatasan dalam mengucapkan kata dan memahami ucapan (Sitorus, 2017). Mereka terkadang menggunakan nada atau intonasi yang aneh didengar atau bahkan datar. Perasaan dan keinginan sulit diekspresikan atau disampaikan kepada oranglain. Pemerolehan bahasa pada anak autis khususnya aspek berbicara yang terjadi sangat lambat membutuhkan waktu yang lama untuk menggunakan kalimat yang baik dan benar. Oleh karena itu, kegiatan bersosialisasi dengan lingkungan sekitar bisa jadi terhambat (Subyantoro, 2013:48).

Penelitian linguistik terdahulu tentang gangguan berbahasa juga mengungkapkan bahwa pengucapan suku kata dan fonem tidak dapat diucapkan dengan jelas oleh anak autis (Farihat \& Chairuddin, 2020). Biasanya mereka mengungkapkan kata yang terdengar tidak lengkap. Sebagai contoh kalimat 'kalau di sekolah' yang terdiri dari enam suku kata menjadi 'ao sola' yang terdiri dari empat suku kata saja. Meskipun mereka dilaporkan mengalami kesulitan dalam berkomunikasi, namun anak tetap berusaha memahami informasi yang disampaikan oleh orang lain dengan cara memperhatikan gerak bibir lawan bicara. Anak autis dapat melakukan kontak mata dengan baik tetapi kesulitan untuk memahami kata-kata yang diungkapkan oleh oranglain. Lebih lanjut, studi terdahulu mengungkapkan bahwa anak autis kesulitan untuk mengucapkan huruf ' $r$ ' dan 'ng' (Ulumudin, 2019). Di sisi lain, sebuah studi mengungkapkan bahwa anak autis memiliki juga memiliki kemampuan yang rendah dalam memahami bacaan dan penalaran matematika(Miller et al., 2017). Kegiatan membaca dan memahami bacaan membutuhkan kemampuan untuk mengenal huruf dan memahami apa makna dari beberapa huruf yang digabung menjadi satu kata dan kalimat. Sedangkan untuk kemampuan matematika, mereka lebih baik dalam mengenal lambang bilangan daripada penalaran seperi pengurangan atau penjumlahan.

Sementara itu, karakteristik kemampuan anak autis dalam memproduksi kosakata telah diungkapkan oleh studi terdahulu. Pertama, kemampuan bahasa ekpresif dan reseptif anak autis bergantung pada tahapan linguistik, IQ non-verbal anak, dan jenis tes yang dilakukan (Arutiunian et al., 2021). Kedua, penguasaan jenis kata yang paling banyak terlihat pada anak autis adalah kata benda (Saleh, 2021). Hal ini karena mereka sering menjumpai contoh nyata di sekitarnya baik berupa gambar maupun benda aslinya. Ketiga, anak autis tipe PDDNOS (Pervasive Developmental Disorder Not Otherwise Specified) memiliki kesulitan dalam memproduksi bahasa (Jampaklay et al., 2018). Mereka mengulang kata atau kalimat yang 
didengar dari lawan bicara ketika tidak memahaminya. Dalam studi tersebut dilaporkan bahwa, anak usia kelas 6 SD yang termasuk kategori autis mampu mengucapkan kalimat (2-5 kata) tetapi terkadang tidak sesuai dengan konteks pertanyaan. Mereka memproduksi bahasa yang tidak dikonsep terlebih dahulu di otak.

Perkembangan bahasa anak autis telah banyak dibahas oleh penelitian terdahulu. Anak autis dengan tipe PDDNOS dilaporkan lebih sering mengulang kata/frasa/kalimat yang sama dengan yang didengar dari lawan bicara dan tidak dapat memahami maksud dari percakapan (Fimawati et al., 2017). Sedangkan penelitian kami membahas tipe autis yang berbeda, yakni autis tipe ringan. Selanjutnya, pada anak 3,5 tahun dengan autis ringan dilaporkan bahwa kemampuan berbicara masih dalam satu kata dan artikulasi sudah dapat dimengerti meskipun belum jelas (Pelangi, 2021). Kemampuan berbahasa anak autis usia sekolah menengah pertama juga dilaporkan bahwa anak hanya mampu menggunakan tidak lebih dari tiga kata dalam satu kalimat (Riccka Bella Priswa Yolanda et al., 2020). Selain itu, studi sebelumnya juga melaporkan bahwa anak autis juga mengalami kesulitan dalam menggunakan kata ganti orang (Mazzaggio \& Shield, 2020). Dalam studi tersebut dijelaskan bahwa kemungkinan anak autis mengalami kesulitan dalam mengusai kemampuan untuk mengidentifikasi secara psikologis dengan orang lain. Identifikasi psikologis dapat membantu anak untuk memahami siapa yang menjadi subjek kalimat yang perlu diucapkan pada lawan bicara. Keterbatasan kemampuan ini mengakibatkan adanya kesalahan penggunaan kata ganti. Meskipun begitu, anak sangat lancar ketika berbicara seperti anak normal pada umumnya. Di sisi lain, penelitian kami menggunakan subjek yang berusia sekolah dasar (8-9 tahun) dengan fokus penelitian pada pengucapan kosakata benda dan kerja. Inilah yang selanjutnya menjadi kebaharuan dalam penelitian kami. Oleh karena itu, penelitian ini bertujuan untuk memberikan gambaran pemerolehan kosakata anak autis kategori ringan.

\section{METODOLOGI}

Penelitian ini menggunakan pendekatan studi kasus yang memiliki fokus pada permasalahan pemerolehan bahasa anak autis ringan. Pendekatan tersebut dipilih karena peneliti ingin mengamati permasalahan secara teliti dan detail sampai tuntas. Studi kasus memungkinkan peneliti memahami individu atau subyek penelitian lebih mendalam. Harapannya, data yang diperoleh dapat digunakan untuk memberikan solusi atas permasalahan subyek penelitian. Dengan demikian, individu akan memiliki karakter, cara berfikir, dan perkembangan yang lebih baik karena didukung oleh lingkungan yang sejalan dengan tumbuh kembangnya saat ini.

Subyek dalam penelitian ini adalah seorang anak ASD di Sekolah Terapi Kembang Mekar Jombang bernama AAN. Ia termasuk pada klasifikasi tipe autis yang memiliki ciri-ciri kualitas dari gangguan tersebut lebih ringan. Anak-anak dalam kategori ini masih bisa bertatap muka, ekspresi facial tidak terlalu datar, dan masih bisa diajak bergurau. Lokasi pengambilan data berada di Sekolah Terapi Kembang Mekar Jombang yang beralamatkan di Jalan Empu Gandring No. 09 Kepanjen-Jombang, Jawa Timur. Metode pengumpulan data yang digunakan adalah wawancara, observasi, dan dokumentasi. Metode wawancara dilakukan bersama dengan guru untuk mengetahui profil lembaga (lihat Tabel 1. Pedoman Wawancara). Metode observasi digunakan untuk mengamati bagaimana pengucapan kosakata dari subyek. Sedangkan dokumentasi digunakan untuk melihat ekspresi dan tingkah laku anak.

Format instrumen observasi menggunakan lembar pengamatan yang biasa digunakan oleh sekolah. Selanjutnya, kami menggunakan media bantu untuk melakukan observasi produksi kosakata yang bisa diucapkan oleh subyek penelitian. Media yang digunakan berupa gambar benda (buah, hewan, kendaraan, dan benda lain yang sering dijumpai anak). Selain itu, subyek penelitian juga ditunjukkan gambar aktivitas sehari-hari. Data yang telah diperoleh dari hasil wawancara ditranskip dan dibuat kesimpulan. Pengambilan data dilakukan secara kolaboratif dengan guru kelas. Instrumen digunakan oleh peneliti, 
sedangkan stimulasi pembelajaran dilakukan oleh guru kelas. Proses pengamatan dilakukan secara kolaboratif antara guru kelas dan peneliti.

Tabel 1. Pedoman Wawancara

\begin{tabular}{ll}
\hline No & \multicolumn{1}{c}{ Kisi-kisi Pertanyaan } \\
\hline $\mathbf{1}$ & Jenis layanan \\
$\mathbf{2}$ & Jenis terapi yang dilakukan \\
$\mathbf{3}$ & Jenis ABK yang ditangani \\
$\mathbf{4}$ & Tindak lanjut hasil pengamatan \\
\hline
\end{tabular}

Format instrumen observasi menggunakan lembar pengamatan yang biasa digunakan oleh sekolah. Selanjutnya, kami menggunakan media bantu untuk melakukan observasi produksi kosakata yang bisa diucapkan oleh subyek penelitian. Media yang digunakan berupa gambar benda (buah, hewan, kendaraan, dan benda lain yang sering dijumpai anak). Selain itu, subyek penelitian juga ditunjukkan gambar aktivitas sehari-hari. Data yang telah diperoleh dari hasil wawancara ditranskip dan dibuat kesimpulan. Selanjutnya, data dari hasil observasi juga ditranskip agar lebih mudah ketika mengidentifikasi hasil produksi kata yang diucapkan subyek. Peneliti kemudian memilah dan mengelompokkan kata yang diucapkan apakah kata kerja atau kata benda. Kejelasan dari setiap kosakata juga menjadi temuan untuk mengidentifikasi huruf apa yang tidak jelas diucapkan.

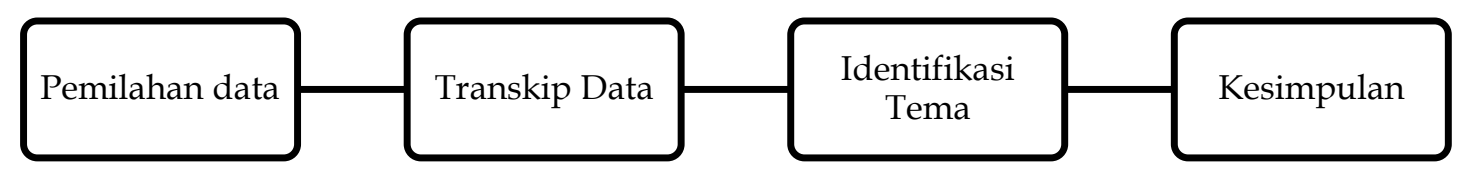

\section{HASIL DAN PEMBAHASAN}

\section{Gambar 1. Proses Analisis Data Penelitian}

Hasil dari penelitian ini memunculkan tiga tema yang berbeda. Tema tersebut adalah profil di lokasi penelitian, pemerolehan kata benda, dan pemerolehan kata kerja.

\section{Profil Sekolah Terapi Kembang Mekar Jombang}

Berdasarkan hasil wawancara, Sekolah Terapi Mekar Jombang memiliki lima jenis layanan yang terdiri dari pengasuhan anak, kelompok bermain, taman kanak-kanak inklusi, dan terapi. Setiap anak yang masuk diidentifikasi terlebih dahulu usia dan kebutuhan perkembangannya. Biasanya lembaga ini menerima siswa dariusia 1.5 sampai 2 tahun dengan gangguan speech delay. Ada juga yang baru usia 10 tahun memasukkan ke layanan tumbuh kembang dikarenakan kesibukan orangtua sebagaimana diungkapkan oleh partisipan berikut ini.

"1.5-2 tahun biasanya speech delay. Ada juga yang 10 tahun baru masuk ke sini karena orangtua belum mengerti dan tahun ini lebih banyak berasal dari luar kota. Kebanyakan orangtua yang bekerja tidak sadar jika anaknya membutuhkan terapi karena pulangnya sore terus."

Perkembangan anak yang terlambat karena faktor ketidakhadiran orangtua dalam pengasuhan juga dilaporkan oleh studi terdahulu (Jampaklay et al., 2018). Kehadiran orangtua terutama ibu dalam aktivitas keseharian anak menjadi hal yang krusial untuk pertumbuhan dan perkembangan anak. Meskipun ibu bukan pengasuh utama karena harus bekerja di luar rumah, mereka bisa tetap menciptakan kelekatan dengan anak dengan cara menyanyikan lagu atau cerita sebelum anak-anak tidur. Selain itu, ibu juga dapat bertanya kepada anak kegiatan apa saja yang hari ini mereka lakukan. Dengan demikian, tahapan tumbuh kembang anak masih bisa terkontrol dengan baik.

Selanjutnya, lembaga ini memberikan berbagai jenis terapi sesuai dengan kebutuhan khusus anak. Misanya saja untuk anak autis, sekolah memberikan terapi wicara, perilaku, dan 
motorik. Setiap pemberian stimulasi dilakukan secara terintegrasi antara terapi satu dengan yang lain. Meskipun ada anak autis yang hanya butuh terapi wicara, namun terapi lain akan tetap diberikan karena saling mempengaruhi sebagaimana diungkapkan oleh partisipan berikut ini.

"Sesuai kebutuhan anak, misal anak autis ada terapi wicara, perilaku, dan motorik kasar, dan halus. Jadi misal dia butuuh terapi wicara, namun juga perkembangan lain bisa mempengaruhi jadi tetap diberikan terapi komplit"

Media yang digunakan untuk terapi disediakan sesuai panduan yang diberikan sekolah. Guru menggunakan panduan lalu mengembangkan media agar sesuai dengan karakteristik anak didik. Senada dengan penelitian terdahulu yang menyatakan bahwa guru menggunakan strategi yang disesuaikan dengan kondisi atau permasalahan siswa ketika menstimulasi keterampilan berbicara anak autis (Yazici \& McKenzie, 2020). Dalam studi tersebut dijelaskan guru menggunakan rencana pembelajaran individual. Selain terapi, lokasi penelitian juga bekerjasama dengan rumah sakit. Mereka berkonsultasi dan berdiskusi terkait perkembangan dengan dengan dokter tumbuh kembang sebagaimana diungkapkan oleh partisipan berikut ini

"Kalau dari sekolah langsung ke rumah sakit. Jadi ke dokter tumbuh kembang."

Konsultasi dengan dokter tentu sangat diajurkan bagi anak berkebutuhan khusus. Menentukan kriteria prognostik untuk anak autis sangat penting untuk intervensi peekembangan dan rehabilitasi seumur hidup (Celik et al., 2021). Jika membawa anak autis ke rumah sakit, maka guru perlu memperhatikan beberapa hal yang mungkin akan membuat anak tertekan dengan adanya suara, bau, dan pemandangan visual yang baru (Iannuzzi et al., 2015).

\section{Pemerolehan Kata Benda (Nomina)}

Tabel 1. Hasil Pemerolehan Kata Benda

\begin{tabular}{lllllll}
\hline No. & Materi & artikulasi & artikulasi & artikulasi & artiklasi & Artikulaso \\
\hline 1. & semangka & [semaka] & [semangka] & [semangka] & [semangka] & [semanka] \\
2. & Kelapa & [kelapa] & [kelapa] & [kelapa] & [kelapa] & [kelapa] \\
3. & Jeruk & [jeluk] & [jeluk] & [jeluk] & [jelu] & [jelu] \\
4. & Kelinci & [kewinci] & [kewinci] & [kewinci] & [kewici] & [kewinci] \\
5. & Kucing & [kucing] & [kucing] & [kucing] & [kucing] & [kuci] \\
6. & Gunting & [gunti] & [guting] & [gunting] & [guting] & [gutin] \\
7. & Krayon & [krayo] & [krayo] & [krayo] & [krayo] & [kwaya] \\
\hline
\end{tabular}

Berdasarkan data pada Tabel 1 diperoleh hasil bahwa kata semangka yang dilafalkan oleh siswa Autis adalah kata [semaka], [semangka], [semangka], dan [semanka]. Ada beberapa fonem [ng] dan [g] yang hilang. Kedua, kata [kelapa] pada pelafalan pertama [kelapa], diulang empat kali menunjukkan kesesuaian pelafalan. Ketiga, objek kesulitan mengucapkan [r] pada kata jeruk yamg diucapkan [jeluk], [jeluk], [jeluk], [jelu], [jelu]. Fonem $\mathrm{k}$ justru dihilangkan pada pelafalan ke empat dan kelima. Keempat, kata kelinci dilafalkan [kewinci], [kewinci], [kewinci], [kewici], dan [kewinci]. Pada pelafalan pertama sampai ketiga terjadi perubahan fonem [1] menjadi [w] yan dilafalkan empat kali. Kelima, kata kucing dilafalkan [kucing], [kucing], [kucing], [kucing], dan [kuci]. Terjadi penghilangan bunyi senagau [ng] di pelafalan terakhir. Keenam, kata gunting dilafalkan [gunti]. [guting]. [gunting],[guting],[gutin]. Terjadi penghilangan [ng], [n], dan [g]. Ketujuh, kata krayon dilafalkan [krayo], [krayo], [krayo], [krayo], dan [kwaya]. Terjadipenghilangan pada fonem akhir [n] dan di akhir pelafalan ada dua perubahan fonem yaitu fonem [r] menjadi [w] dan vokal [o] berubah menjadi [a]. 


\section{Pemerolehan Kata Kerja (Verba)}

Ada tiga kosa kata yang ditemukan peneliti. Berdasarkan data pada Tabel 2 dihasilkan melalui proses percakapan peneliti dengan objek penelitian dengan menunjukkan gambar yang dilakukan berulang-ulang. Hasil perolehan kosa kata yang dilakukan peneliti dengan siswa autis melalui proses percakapan dengan media menunjukkan gambar orang yang sedang berlari. Objek menghasilkan kata dengan cara diucapkan yaitu kata [melari]. Kata [melari] bermakna berlari. Kata yang diujarkan siswa autis merupakan bentuk dasar dari kata lari. Siswa autis yang diteliti tidak dapat mengucapkan kata berlari tetapi kata [melari]. Kata berlari mengalami perubahan fonem awal yaitu [b] menjadi [m] dan mengalami penghilangan fonem [r]. Jadi, pemerolehan kosa kata anak autis mengalami penyederhaan kata karena kelemahan yang menyebabkan terhambatnya kegiatan berkomunikasi dengan lingkungan sekitar.

Tabel 2. Hasil Pemerolehan Kata Kerja

\begin{tabular}{lllllll}
\hline No. & Materi & artikulasi & artikulasi & artikulasi & artiklasi & Artikulaso \\
\hline 1. & berlari & [melari] & [melari] & [malari] & [malari] & [melari] \\
2. & bermain bola & [main] & [maen] & [maen-maen] & [maen] & [maen] \\
3. & mengepel & [ngepel] & [ngepel] & [ngepel] & [ngepel] & [ngepel] \\
\hline
\end{tabular}

Kedua, melalui proses percakapan dan menunjukkan gambar orang yang sedang bermain bola. Kata [main bola] bermakna bermain bola. Kata [main] yang diujarkan siswa autis merupakan bentuk dasar dari kata bermain. Siswa autis yang diteliti tidak dapat mengucapkan kata bermain tetapi kata [main]. Berikutnya fonem \{i] berubah menjadi [e] pada kata [maen]. Pelafalan berikutnya mengalami perulangan menjadi [maen-maen]. Hal ini disebabkan oleh faktor lingkungan yang kurang mendukung, yang masih menggunakan bahasa sehari-hari. Dengan demikian, pemerolehan bahasa anak autis didapat dengan merespon ujaran yang didengarnya dari lingkungan seharihari yang masih menggunakan bahasa Jawa dalam berkomunikasi.

Ketiga, proses percakapan dan menunjukkan gambar yang ingin ditanyakan pada siswa autis bahwa kata yang diucapkan siswa adalah [ngepel]. Kata [ngepel] bermakna mengepel. Kata yang diujarkan siswa autis merupakan bentuk dasar dari kata mengepel. Siswa autis yang diteliti tidak bisa mengucapkan kata mengepel tetapi [ngepel]. Hal ini dikarenakan oleh faktor lingkungan keluarga yang menggunakan Bahasa Jawa. Oleh karena itu, pemerolehan bahasa anak autis didapat dengan merespon ujaran yang didengarnya dari lingkungan sehari-hari yang masih menggunakan bahasa Jawa. Penggunaan bahasa jawa sebagai bahasa pertama juga ditemukan pada studi terdahulu yang menyatakan bahwa pengucapan huruf hijaiyah pada anak autis menjadi berubah (Alvin \& Ferawati, 2020). Huruf hijaiyah yang terdengar mirip dengan suku kata bahasa jawa menyulitkan anak untuk membedakan keduanya. Selain itu, perubahan bunyi bisa juga terjadi karena letak artikulasi atau tempat produksi bunyi suara berdekatan.

Hasil penelitian menunjukkan bahwa pengucapan kosakata pada anak autis ringan menghilangkan dan mengubah huruf konsonan pada kata benda dan kata kerja. Huruf konsonan yang hilang seperti [g], [ng], [k], [n], [r] dan huruf yang berubah [r], [1], [o], [b],[i]. Mereka juga kesulitan menggunakan kata kerja berimbuhan seperti [ber] dan [me]. Hal ini didukung oleh penelitian sebelumnya yang melaporkan bahwa ketika berbicara anak autis lebih sulit mengucapkan huruf konsonan daripada vokal (Utami et al., 2021). Hal ini karena huruf konsonan melibatkan pergerakan mulut dan lidah. Kesalahan pengucapan sering kali ditemukan pada anak autis (Pomper et al., 2019). Selain itu, anak autis juga dilaporkan mengalami kesulitan dalam memahami makna dan hubungannya dengan benda dari suatu kata (Floyd et al., 2021). Oleh karena itu, belajar kosakata akan lebih sulit mereka lakukan. Lebih lanjut, studi terdahlu mengungkapkan bahwa anak autis memproduksi pola suara atau 
bunyi yang tidak biasa (Wolk \& Brennan, 2013). Bahkan terkadang sebuah kata terdengar seperti bunyi siulan.

Berbagai penelitian sebelumnya menemukan bahwa stimulasi bahasa pada anak autis dapat dilakukan dengan berbagai macam metode. Pertama, musik dilaporkan dapat meningkatkan penguasaan keterampilan komunikasi anak autis (Fong \& Lee, 2012). Musik digunakan sebagai media untuk belajar anak. Ketika mendengarkan musik, peneliti mengajak anak untuk menggunakan tangannya melakukan berbagai gerakan, gesture dengan cara menunjukkan ekspresi pada anak agar ia menirukan, sentuhan (menyentuh atau mendorong bagian tubuh anak untuk memberi tanda suatu gerakan), dan perintah lisan (memanggil namanya untuk melihat reaksinya). Setelah diberikan intervensi musik selama 12 kali pertemuan, anak dapat berinteraksi secara verbal dan menjawab pertanyaan oranglain dengan lebih baik dari sebelum diberikan perlakuan. Kedua, metode bercerita atau menggambarkan suatu hal. Dalam sebuah studi diungkapkan bahwa ayah dengan anak autis lebih banyak memberikan deskripsi suatu benda atau peristiwa daripada memberi anak pertanyaan (Bentenuto et al., 2021). Metode ini menunjukkan bahwa pendidiklah yang sebaiknya menyesuaikan kemampuan verbal anak, bukan sebaliknya. Ketika mengajak anak berbicara, maka orang dewasa yang menyesuaikan dengan tingkat kemampuan anak. Selain itu, stimulasi juga dilakukan dengan melibatkan kegiatan fisik tidak dominasi verbal.

Ketiga, stimulasi bahasa menggunakan teknologi bantu seperti penggunaan aplikasi belajar di komputer. Studi terdahulu menunjukkan adanya perbedaan hasil belajar anak autis menggunakan teknologi bantu dan pembelajaran konvesional (Fteiha, 2017). Program atau aplikasi yang ditampilkan pada layar komputer memberikan penguatan pada anak ketika belajar. Media ini menyediakan lingkungan belajar yang kaya akan stimulasi visual dan auditori. Informasi yang diterima melalui audio-visual terbukti lebih baik daripada hanya melalui auditori saja. Keempat, studi menunjukkan bahwa stimulasi perkembangan anak autis dapat dilakukan melalui son-rise program (SRP) (Supena et al., 2022). Program tersebut menekankan pada peran lingkungan (orangtua dan keluarga) yang terlibat secara bersama untuk mendorong interaksi sosial dan bahasa anak autis menjadi lebih baik. Interaksi antar dengan anak dibangun dengan cara memberikan motivasi dan fleksibilitas waktu yang efektif. Salah satu caranya adalah dengan menyediakan ruang bermain dan konsep bermain yang disediakan oleh fasilitator untuk membangun interaksi dengan anak dan meminimalisir perilaku yang bermasalah pada anak.

Terbatasnya subyek yang diobservasi menjadi salah satu kelemahan penelitian kami. Kesimpulan dari hasil data yang diperoleh belum kuat untuk dijadikan sebagai generalisasi kondisi anak autis ringan. Oleh karena itu, diperlukan studi lebih lanjut mengenai pemerolehan kosakata kerja dan benda pada anak autis ringan. Kemudian, kami juga belum mengobservasi jenis kata keterangan dan kata sifat yang diucapkan anak.

\section{SIMPULAN}

Pengucapan kosakata pada anak autis ringan mengalami perubahan pada kata benda yang memilki huruf [r], [1], [g], [n], dan [ng]. Sedangkan untuk kata kerja mereka kesulitan untuk menggunakan kata berimbuhan. Meskipun demikian, anak autis kategori ringan pada ucapan pertama masih menunjukkan pengucapan yang benar. Agar pengucapan menjadi lebih jelas dan tepat, anak autis perlu diberikan stimulasi bahasa yang tepat melibatkan orangtua dan keluarga. Hasil penelitian ini dapat menjadi rujukan bagi orangtua dan lembaga sekolah yang menangani anak autis kategori ringan sebagai dasar pemberian intervensi yang tepat.

\section{UCAPAN TERIMA KASIH}

Terimakasih kepada STKIP PGRI Jombang dan Sekolah Terapi Kembang Mekar Jombang yang telah mendukung penelitian ini. 


\section{DAFTAR PUSTAKA}

Alvin, N. F., \& Ferawati, F. (2020). The Pronunciation of the Hijaiyah Letters for Autistic Children at Extraordinary Islamic School Qothrunnada Yogyakarta. Al-Misbah (Jurnal Islamic Studies), 8(1), 31-38. https:// doi.org/10.26555/almisbah.v8i1.1906

Arutiunian, V., Lopukhina, A., Minnigulova, A., Shlyakhova, A., Davydova, E., Pereverzeva, D., Sorokin, A., Tyushkevich, S., Mamokhina, U., Danilina, K., \& Dragoy, O. (2021). Expressive and Receptive Language in Russian Primary-School-Aged Children with Autism Spectrum Disorder. Research in Developmental Disabilities, 117(June), 104042. https:// doi.org/10.1016/j.ridd.2021.104042

Bentenuto, A., Perzolli, S., Bertamini, G., Venuti, P., \& de Falco, S. (2021). Paternal speech directed to young children with Autism Spectrum Disorders and typical development. Research in Developmental Disabilities, 112(January), 103886. https:// doi.org/10.1016/j.ridd.2021.103886

Callen, M. C., \& Miller, K. (2021). Linguistic Variation in the Acquisition of Morphosyntax: Variable Object Marking in the Speech of Mexican Children and Their Caregivers. Language Learning and Development, 00(00), 1-14. https://doi.org/10.1080/15475441.2021.1977133

Celik, H., Acikel, S. B., Ozdemir, M. A. F., Aksoy, E., Oztoprak, U., Ceylan, N., \& Yuksel, D. (2021). Evaluation of the clinical characteristics of children with autism spectrum disorder and epilepsy and the perception of their parents on quality of life. Epilepsy Research, 172(March), 106599. https:/ / doi.org/10.1016/j.eplepsyres.2021.106599

Chaer, Abdul. 2003. Psikolinguistik Kajian Teoretik. Jakarta: PT Rineka Cipta . 2007. Linguistik Umum. Jakarta: Rineka Cipta.

Dardjowidjojo, Soejono. 2016. Psikolinguistik Pemahaman Bahasa Manusia. Jakarta: Yayasan Pustaka Obor Indonesia

Djajasudarma, Fatimah. 2010. Metode Linguistik (Ancangan Metode Penelitian dan Kajian). Bandung: PT. Refika Aditama

Farihat, W. N., \& Chairuddin. (2020). The portrait of autism language disorder of Indonesian students (linguistics study). SELL Journal: Scope of English ..., 58-66. http://www.publikasi.stkippgri-bkl.ac.id/index.php/SL/article/view/359

Fimawati, Y., Dhanawaty, N. M., \& Sukarini, N. W. (2017). Kemampuan Berbahasa Anak Autis Tipe Pddnos Di Slb Muhammadiyah Sidayu Gresik: Kajian Psikolinguistik. Linguistika, 24(47), 203-220.

Floyd, S., Jeppsen, C., \& Goldberg, A. E. (2021). Brief Report: Children on the Autism Spectrum are Challenged by Complex Word Meanings. Journal of Autism and Developmental Disorders, 51(7), 2543-2549. https://doi.org/10.1007/s10803-020-04687-x

Fong, C. E., \& Lee, C. S. (2012). Communication Responses of an Indian Student with Autism to Music Education. Procedia - Social and Behavioral Sciences, 65(ICIBSoS), 808-814. https:// doi.org/10.1016/j.sbspro.2012.11.203

Fteiha, M. A. (2017). Effectiveness of assistive technology in enhancing language skills for children with autism. International Journal of Developmental Disabilities, 63(1), 36-44. https:// doi.org/10.1080/20473869.2015.1136129

Hikmawati, Y. (2014). Pemerolehan Bahasa pada Anak Autis: Kajian Psikolinguistik. Indonesian Language Education and Literature, Vol. 6, No(No. 1, Desember 2020,), 104-118. https://doi.org/10.24235/ileal.v6i1.6689

Iannuzzi, D., Kopecky, K., Broder-Fingert, S., \& Connors, S. L. (2015). Addressing the Needs of Individuals with Autism: Role of Hospital-Based Social Workers in Implementation of a Patient-Centered Care Plan. Health and Social Work, 40(3), 245-248. https:// doi.org/10.1093/hsw/hlv032

Jampaklay, A., Richter, K., Tangchonlatip, K., \& Nanthamongkolchai, S. (2018). The impact of parental absence on early childhood development in the context of Thailand. Asian and Pacific Migration Journal, 27(2), 209-230. https://doi.org/10.1177/0117196818767439 
Liza, N., Kuntarto, E., \& Kusmana, A. (2020). Pemerolehan Bahasa Anak Berkebutuhan Khusus (Tunarungu) Dalam Memahami Bahasa. Jermal, 1(2), 89-97. https://doi.org/10.31629/jermal.v1i2.2214

Mar'at, S. (2005). Psikolinguistik Suatu Pengantar. PT Refika Aditama.

Mazzaggio, G., \& Shield, A. (2020). The Production of Pronouns and Verb Inflections by Italian Children with ASD: A New Dataset in a Null Subject Language. Journal of Autism and Developmental Disorders, 50(4), 1425-1433. https://doi.org/10.1007/s10803-019$\underline{04349-7}$

Miller, L. E., Burke, J. D., Troyb, E., Knoch, K., Herlihy, L. E., \& Fein, D. A. (2017). Preschool predictors of school-age academic achievement in autism spectrum disorder. Clinical Neuropsychologist, 31(2), 382-403. https://doi.org/10.1080/13854046.2016.1225665

Pelangi, G. (2021). Kemampuan Berbahasa pada Anak Autis Ringan Usia 3,5 Tahun (Studi $\begin{array}{llll}\text { Kasus Autis Hiperaktif). } & \text { Deiksis, }\end{array}$ https://doi.org/10.30998/deiksis.v13i3.8164

Pomper, R., Ellis Weismer, S., Saffran, J., \& Edwards, J. (2019). Specificity of Phonological Representations for Children with Autism Spectrum Disorder. Journal of Autism and Developmental Disorders, 49(8), 3351-3363. https://doi.org/10.1007/s10803-019$\underline{04054-5}$

Riccka Bella Priswa Yolanda, Joko Hariadi, \& Muhammad Taufik Hidayat. (2020). Penggunaan Bahasa Anak Autis Di Smplb Kota Langsa. Tahun 2020. Samudra Bahasa, 41-51.

Saleh, M. (2021). Mastery of Indonesian Vocabulary in Autistic Children. HUMAN: South Asean Journal of Social Studies, 1(2), 162-171.

Sitorus, C. R. N. (2017). Language Disorder In Autistic Children At Yayasan Tali Kasih Medan: A Psycholinguitics Analysis. In A Thesis (Vol. 1, Issue 3).

Supena, A., Nuryanti, \& Karnadi. (2022). Efektifitas Son-Rise Program dalam Meningkatkan Keterampilan Bahasa, Sosial Komunikasi pada Anak Autis. Surnal Obsesi: Jurnal Pendidikan Anak Usia Dini, 6(4), 315-338. https:/ / doi.org/10.31004/obsesi.v6i1.1268

Ulumudin, I. (2019). Penggunaan Media Gambar Untuk Mengembangkan Penguasaan Kosakata Pada Anak Autis Usia Dini. JIV-Jurnal Ilmiah Visi, 14(1), 75-84. https://doi.org/10.21009/JIV.1401.8

Utami, K., Darmayanti, N., Amalia, R. M., \& Sidiq, I. I. (2021). Pronunciation of Indonesian Language Consonant by Students with Autism in Bintang Harapan Special Needs School: A Psycholingustic Analysis. International Journal of Early Childhood Special Education, 13(2), 39-48. https:/ / doi.org/10.9756/INT-JECSE/V13I2.211037

Wolk, L., \& Brennan, C. (2013). Phonological investigation of speech sound errors in children with autism spectrum disorders. Speech, Language and Hearing, 16(4), 239-246. https://doi.org/10.1179/2050572813Y.0000000020

Yazici, M. S., \& McKenzie, B. (2020). Strategies Used to Develop Socio-Communicative Skills among Children with Autism in a Turkish Special Education School and Implications for Development of Practice. International Journal of Disability, Development and Education, 67(5), 515-535. https:/ / doi.org/10.1080/1034912X.2019.1614152 